\title{
Cut Off Point of Telomere Length and Association With Blood Glucose and Lipid Profile Among Minangkabau Ethnic Women
}

\author{
Yuniar Lestari ${ }^{1}$, Ulya Uti Fasrini ${ }^{2}$, Afriwardi $^{3}$, Ricvan Dana Nindrea ${ }^{4}$, Alief Dhuha ${ }^{5}$ \\ \{yuniarlestari@med.unand.ac.id ${ }^{1}$ \} \\ Department of Public Health and Community Medicine, Faculty of Medicine, Universitas Andalas \\ Padang, Indonesia ${ }^{1,4}$ \\ Department of Nutrition, Faculty of Medicine, Universitas Andalas Padang, Indonesia ${ }^{2}$ \\ Department of Physiology, Faculty of Medicine, Universitas Andalas Padang, Indonesia ${ }^{3}$ \\ Department of Neurosurgery, Faculty of Medicine, Jhici Universiy, Japan ${ }^{5}$
}

\begin{abstract}
The aim of this study to determine the cutoff point of telomere length and association with blood glucose and lipid profile among Minangkabau ethnic women. This cross-sectional study was conducted in Padang City, Indonesia using a sample of 116 Minangkabau ethnicity women aged between $40-55$ years. The blood sample analysis using O'Callaghan and Fenech's technique to measure telomere length, fasting blood glucose and lipid profile analysis from blood venous. Data analysis using Pearson correlation and then continued for known cut off point by Hosmer-Lemeshow test. Data were processed using Stata version 14.2 (Stata Corporation). The results showed there is no correlation between blood glucose and profile lipid (total cholesterol, LDL, HDL, and triglycerides) with telomere length of Minangkabau ethnicity women ( $>0.05)$. Based on receiver operating characteristic (ROC) curve analysis, we obtained a cutoff point for telomere length is $385 \mathrm{bp}$ with $53 \%$ sensitivity, 55\% specificity and an accuracy of $58.2 \%$. Blood glucose and lipid profile do not have correlation because of telomere length cause of many factors. This analysis confirmed there is no correlation blood glucose and profile lipid with telomere length of Minangkabau ethnicity women. Cut off point for predicted telomere length is $385 \mathrm{bp}$.
\end{abstract}

Keywords: : Blood Glucose, Lipid Profile, Telomere Length, Women, Minangkabau.

\section{Introduction}

One important indicator of a national population's health status is life expectancy. IT is still relatively low in developing countries compared to developed countries. The average life expectancy worldwide has increased from 67 years in 2009 to 71 years in 2013 [1] in Southeast Asia, which is composed of mainly developing countries the average life expectancy was 71 years in 2013. Indonesia is one of the countries in Southeast Asia has life expectancy Indonesia reached 70.1 years, still falling short of the national target of 72 years. In the province of West Sumatra in Indonesia life expectancy is only 67.9 years [1]-[3]. One of the biomarkers can predict life expectancy is telomere length. Telomeres are nucleoprotein complexes at the ends of eukaryotic chromosomes and DNA molecules [4]. Telomere shortening occurs due to the failure to synthesize the most part ends in a linear DNA molecule during ordinary DNA 
replication. Hence, telomeres gradually become shorter with age. Cell culture studies show lifespan is limited by telomere shortening, a natural process that begins with the onset of aging at the cellular level and occurs as diploid cells lose telomeres at cell division due to the failure of this process to synthesize the further most ends in a linear DNA molecule [4],[5].

The lengths of human telomeres are normally reduced by approximately $24.8-27.7$ base pairs per year [6]. Progressive telomere shortening is caused by aging, apoptosis, or oncogenic transformation of somatic cells. Shorter telomere length has been associated with an increased incidence of disease, organ malfunctions, poor recovery from illness and premature death [4],[7].

Accumulating evidence indicates that high blood glucose and may affect changes in telomere length. Previous study knew an association between type 2 diabetes mellitus (T2DM) and shortened telomere length [8]. Similarly, determined that the leukocyte telomere length in patients with diabetes was shorter than that in healthy individuals [9]. Another study demonstrates a close association between diabetes mellitus and telomere length, which was influenced by region, age, diabetes type, BMI and sex [10].

Another factor can cause shortening telomere length is the atherogenic properties of elevated cholesterol and triglycerides confer repeated mechanical, hemodynamic, and/or immunological injury and, as such, may cause augmented cell turnover and increased production of Reactive Oxygen Species (ROS) in certain cells. The link between cholesterol and TL may be secondary to increased cell damage and turnover, which in turn amplifies cell aging by bringing cells to their maximum replicative capacity - translating to shortened telomere length. This could also tie in with age-related innate immune pathway activation in adipose tissue and its link with subclinical chronic inflammation [11].

\section{Methods and Materials}

\subsection{Study design and research sample}

This cross-sectional study was conducted subdistrict of Padang City from March 2016 to Augustus 2017. This study was performed on 116 Minangkabau ethnic women, aged 40-50 years worked as a housewife. Minangkabau ethnic means if both the parents and the ancestors are Minangkabau people. The sample size was calculated using the formula for continuous data on population.

\subsection{Operational definitions}

The variables of this study included independent variable is fasting blood glucose, lipid profile and the dependent variable is telomere length Minangkabau ethnic.

\subsection{Data collection technique}

The Ethical Committee of Medical Faculty approved this study, Universitas Andalas with registration number 051/KEP/FK/2016. Blood samples were drawn from all subject $(5 \mathrm{~mL})$ and stored into EDTA containing tubes for lab transfer. Blood samples were centrifuged at 1000 rpm for $10 \mathrm{~min}$ at 4EC and stored at -70EC for DNA extraction. Genomic DNA was extracted with Qiagen (QIAamp DNA Blood Mini Kit, Germany) and quantified by spectrophotometer 
(Hitachi 1800, Japan). Samples were run by Multiplex Real-Time PCR BioradCFX 96 TM detection system with TM Software CFX manager. Telomere length was measured using O'Callaghan and Fenech15 technique. The level of glucose in the blood measured after an overnight fast.

\subsection{Data analysis}

The quantitative variables were recorded as Mean $\pm \mathrm{SD}$, median and percentage. The correlation was analyzed by using Pearson's correlation. A two-tailed $P$-value of $<0.05$ was considered statistically significant. Cut off point analysis using receiver operating characteristic (ROC) curve; the results show sensitivity, specificity, and accuracy. Data were analyzed using the Stata version 14.2 (Stata Corporation).

\section{Results}

Characteristic of respondents (Table 1)

Table 1. Characteristics of respondents.

\begin{tabular}{ll}
\hline Variable & $\begin{array}{l}\text { Minangkabau Ethnicity Women } \\
(\text { Mean } \pm \mathrm{SD})\end{array}$ \\
\hline Age (years) & $48.1 \pm 5.1$ \\
Body mass index $\left(\mathrm{kg} / \mathrm{m}^{2}\right)$ & $26.14 \pm 4.82$ \\
Systolic blood pressure $(\mathrm{mmHg})$ & $119.30 \pm 15.77$ \\
Diastolic blood pressure $(\mathrm{mmHg})$ & $76.26 \pm 11.11$ \\
\hline
\end{tabular}

Table 1 showed the age of respondents $48.1 \pm 5.1$ years, body mass index $26.14 \pm 4.82 \mathrm{~kg} / \mathrm{m}^{2}$, systolic blood pressure $119.30 \pm 15.77 \mathrm{mmHg}$ and diastolic blood pressure $76.26 \pm 11.11$ $\mathrm{mmHg}$.

Correlation between blood glucose and profile lipid (total cholesterol, LDL, HDL, and triglycerides) with telomere length of Minangkabau ethnicity women (Table 2)

Table 2. Correlation between blood glucose and profile lipid (total cholesterol, LDL, HDL, and triglycerides) with telomere length of Minangkabau ethnicity women

\begin{tabular}{lll}
\hline & Telomere Length & \\
\cline { 2 - 3 } & Pearson correlation $(\mathrm{r})$ & $\mathrm{p}$-value \\
\hline Blood glucose & -0.209 & 0.054 \\
Total cholesterol & -0.035 & 0.706 \\
Low density lipoprotein & -0.001 & 0.992 \\
High density lipoprotein & -0.195 & 0.360 \\
triglycerides & 0.035 & 0.710 \\
\hline
\end{tabular}

Table 2 showed there is no correlation between blood glucose and profile lipid (total cholesterol, LDL, HDL, and triglycerides) with telomere length of Minangkabau women ( $p>0.05)$.

Determination of the cutoff point of telomere length (Figure 1) 


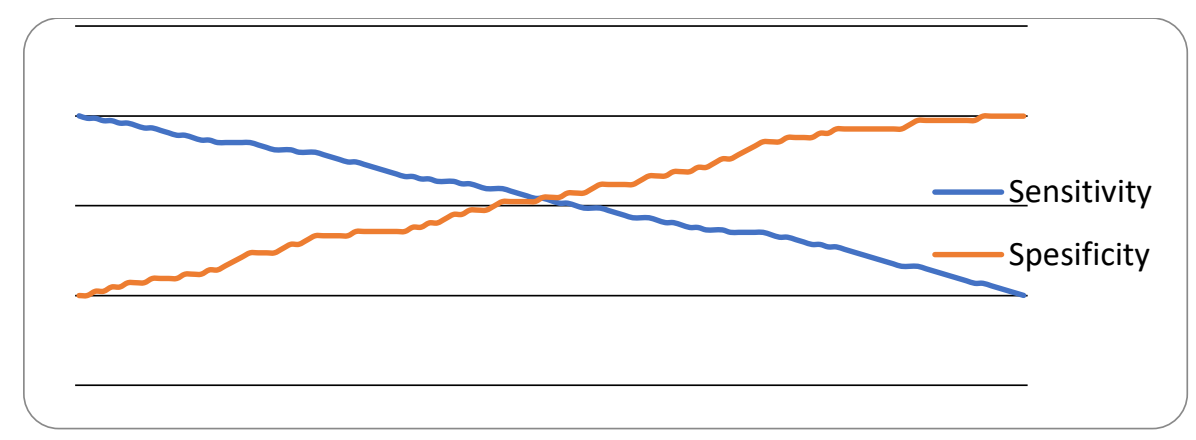

Fig. 1. Determination of the cutoff point of telomere length

Figure 1 showed a cutoff point of telomere length being between points 59 or 60 . The cutoff point from the optimal cut off point of lines and the acquisition of sensitivity and specificity (Table 3).

Table 3. Cut off point from the optimal cut off point of lines and the acquisition of sensitivity and specificity.

\begin{tabular}{llllll}
\hline & Cut off point & Sensitivity & 1 - Specificity & Sensitivity & Specificity \\
\hline 1 & 14.45 & 1 & 1 & & \\
2 & 47.39 & 0.986486486 & 1 & 1 & 0 \\
3 & 84.565 & 0.986486486 & 0.976190476 & 0.986486486 & 0.02381 \\
4 & 92.76 & 0.972972973 & 0.976190476 & 0.972972973 & 0.02381 \\
5 & 99.45 & 0.972972973 & 0.952380952 & 0.972972973 & 0.047619 \\
6 & 111.915 & 0.959459459 & 0.952380952 & 0.959459459 & 0.047619 \\
7 & 120.69 & 0.959459459 & 0.928571429 & 0.959459459 & 0.071429 \\
8 & 124.655 & 0.945945946 & 0.928571429 & 0.945945946 & 0.071429 \\
9 & 130.485 & 0.932432432 & 0.928571429 & 0.932432432 & 0.071429 \\
10 & 133.47 & 0.932432432 & 0.904761905 & 0.932432432 & 0.095238 \\
$\ldots$. & & & & & \\
59 & 384.68 & 0.527027027 & 0.452380952 & 0.527027027 & 0.547619 \\
60 & 390.435 & 0.513513514 & 0.452380952 & 0.513513514 & 0.547619 \\
$\ldots$. & & & & & \\
117 & 2049.77 & 0 & 0 & & \\
\hline
\end{tabular}

Table 3 showed based on analysis, we obtained a cutoff point for telomere length is $385 \mathrm{bp}$ with $53 \%$ sensitivity and 55\% specificity. Accuracy for cut off point of telomere length showed in Receiver Operating Characteristics (ROC) (Figure 2). 


\section{ROC Curve}

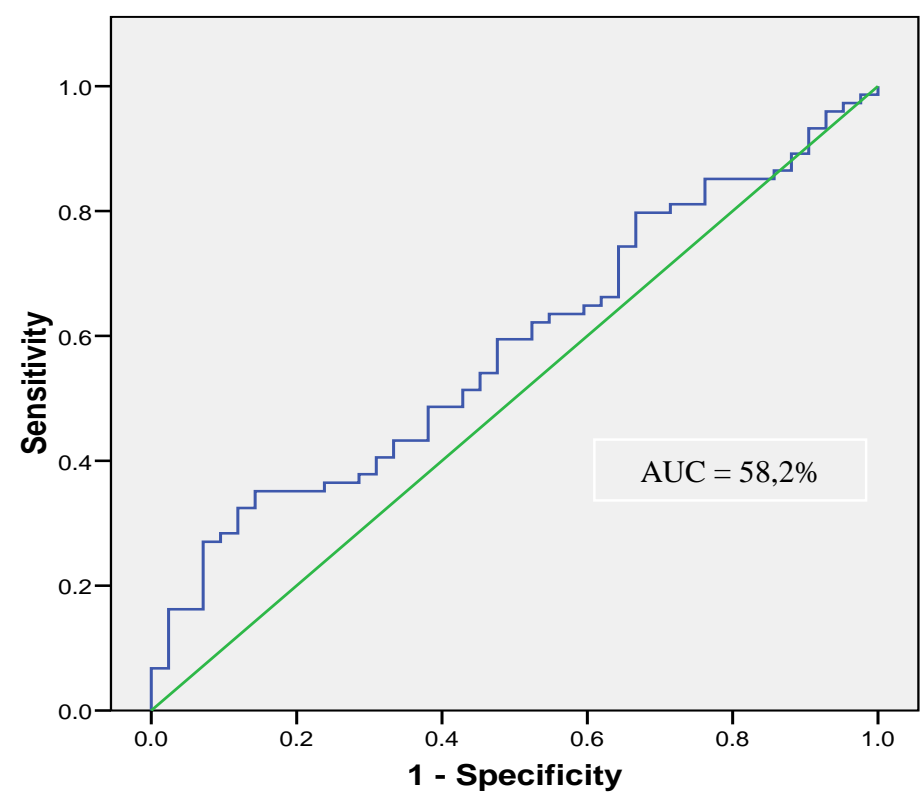

Fig. 2. Receiver Operating Characteristics (ROC) for known accuracy of telomere length cut off point

Figure 2 showed the accuracy of telomere length cut off point is $58,2 \%$, it means enough classification.

\section{Discussion}

The results showed there is no correlation between blood glucose and profile lipid (total cholesterol, LDL, HDL, and triglycerides) with telomere length of Minangkabau women $(p>0.05)$. Based on receiver operating characteristic (ROC) curve analysis, we obtained a cutoff point for telomere length is 385 bp with 53\% sensitivity, 55\% specificity and an accuracy of $58.2 \%$.

Minangkabau is the majority of the population living in West Sumatra and also in the Padang city. The characteristics of Minangkabau women in this study were women in premenopausal conditions and showed that the average Body Mass Index (BMI) was at the level of obesity. Meanwhile, on average, they have normal systolic and diastolic blood pressure.

Minangkabau people have a habit of consuming fat-containing foods. Most Minangkabau foods contain coconut milk and fried foods. Fat consumption reaches $10.6-21.7 \%$ of total energy. Theoretically, the increase in total cholesterol and LDL is caused by an increase in saturated fat and cholesterol consumption. The saturated fat intake of Minangkabau ethnic community reached $18 \%$ which means that it exceeds the recommended number [12]. Minangkabau ethnic total cholesterol and LDL levels are higher than Sundanese, Javanese, and Bugis ethnic [13]. In this study, total cholesterol levels did not correlate with telomere length. 
In theory, the state of hypercholesterolemia plays a role in the production of free radicals which then produce oxidative stress. Oxidative stress is often defined as an imbalance between reactive oxygen species (ROS) and antioxidant capacity in an organism. In this case, antioxidant enzymes such as superoxide dismutase (SOD) and glutathione peroxidase (GPx) play an important role in the first defense for detoxification of products resulting from oxidative stress. In addition, carbonyl proteins (PCs) and F2-isoprostanes are considered as severe oxidate stress biomarkers which are characterized by permanent damage to the structure and function of proteins and also an increase in free radicals induced by lipid peroxidation. There is a significant relationship that is inversely proportional between cholesterol and LDL levels with telomere length will be exacerbated by the nature of atherogenic cholesterol which increases Reactive Oxygen Species (ROS) production [14].

This study also did not get a correlation between fasting blood sugar levels and telomere length. In theory, it has been ascertained that hyperglycemia even in pre-diabetes conditions can induce oxidative stress and eventually lead to cellular aging. Cellular aging and apoptosis occur not only in the vascular endothelium and smooth muscle cells but in several cell lines, including endothelial progenitor cells. Therefore diabetes type 2 can be considered an early aging syndrome [15]. Telomere shortening increases with the length of time suffering from DM. Telomere shortening is longer in subjects who are 10 years or older suffering from diabetes type 2 than healthy subjects $(\mathrm{p}=0.04)$. Followed by telomere shortening between subjects who are 10 years or older suffering from diabetes type 2 with subjects who have one year suffering from diabetes $(\mathrm{p}=0.05)[16]$.

Various factors influence telomere length which is one of the markers of cell aging. Telomeres will shorten according to age. Telomere length will differ in gender, race, BMI, physical activity and illness.

In this study, the average BMI of respondents was in the condition of obesity. Obesity can increase inflammation because white adipose tissue is a major source of inflammatory cytokines. Inflammation promotes an increase in leucocyte cell turnover, which further increases telomere friction. Not surprisingly, obese adults have shorter telomeres than those with normal weight. Seventy people throughout 10-12 years to find out the relationship between obese people with insulin resistance disorders, to find telomere friction. Telomere friction increases with weight gain. It shows that telomere loss is associated with obesity [17].

Another factor in our study, the results showed women in the study included in the premenopausal age group, in this condition a decrease in the hormone estrogen. Oestrogen can diminish oxidative stress and stimulate telomerase production, which protects telomere lengthening and attenuates telomere attrition, an effect that may be lost during menopause [18]. Indeed, this is supported by studies investigating the effect of hormone therapy on telomerase activity that has demonstrated an upregulation of telomerase reverse transcriptase expression. This effect is mediated by the estrogen-responsive element in the gene promoter, thus explaining longer telomeres in postmenopausal women undergoing hormone-replacement therapy. Therefore, low estrogen levels and/or diabetes-induced changes in telomere length might have accounted for the short telomeres [19].

The previous study known cut off point of telomere length for identification mortality, explained by Receiver operating characteristic curves identified a telomere length $<6.28 \mathrm{~kb}$ as a fair predictor of mortality [20]. Finally, reduced telomere length was associated with increased mortality, independently of age, gender and inflammation. Our study found based on receiver operating characteristic (ROC) curve analysis, We obtained a cutoff point for telomere length is $385 \mathrm{bp}(0.35 \mathrm{~kb})$. This study described telomere length in our population shorter than the 
previous study. These things can happen because telomere length has 53\% sensitivity, 55\% specificity and an accuracy of $58.2 \%$.

There were a few limitations in this study. First, researchers do not put attention to internal factors such as levels of the enzyme that can improve telomere length and levels of endogenous antioxidants to reduce oxidative stress can effect shortening telomere length. Second, levels of telomerase enzyme and genetic variation.

Conflict of interest. The authors declare no conflict of interest.

Acknowledgments. We want to thank the Faculty of Medicine, Universitas Andalas for funding this research project (Grant no DIPA-042.01.02.400928/2017) and special thank to all respondents who participated in this study.

\section{References}

[1] World Health Organization. WHO global health observatory data repository: Life expectancydata by country. World Health Organization, Geneva, 2015.

[2] Ministry of Health Republic of Indonesia. Overview of health elderly in Indonesia. Data and Information Center, Jakarta, 2013.

[3] Nindrea RD, Aryandono T, Lazuardi L. Breast Cancer Risk From Modifiable and NonModifiable Risk Factors among Women in Southeast Asia: A Meta-Analysis. Asian Pac J Cancer Prev. 2017; 18: 3201-6.

[4] Shammas MA. Telomeres, lifestyle, cancer and aging. Curr Opin Clin Nutr Metab Care. 2012; 14: $28-34$.

[5] Dickson MA, Hahn WC, Ino Y, Ronfard V, Wu JY, Weinberg RA, et al. Human keratinocytes that express hTERT and also bypass a p16(INK4a)-enforced mechanism that limits life span become immortal yet retain normal growth and differentiation characteristics. Mol Cell Biol. 2000; 20: 1436-47.

[6] Zakian VA. Structure, function, and replication of Saccharomyces cerevisiae telomeres. Annu Rev Genet. 1996; 30; 141-172.

[7] Sulastri D, Lestari Y, Afriwardi, Desmawati. Relationship between body composition and smoking habit with telomere length of Minangkabau ethnicity Men in West Sumatera, Indonesia. Pak J Biol Sci. 2017; 20: 516-22.

[8] Jeanclos E, Krolewski A, Skurnick J, Kimuwa M, Aviv H, Warram JH, Aviv A. Shortened telomere length in white blood cells of patients with IDDM. Diabetes. 1998; 47: 482-6.

[9] Li FZ, Chen YX, He JJ. Telomere and diabetes (in Chinese). Chinese Chronic Disease Prevention and Control. 2014; 22: 604-606.

[10] Wang J, Dong X, Cao L, Cao L, Sun Y, Qiu Y, et al. Association between telomere length and diabetes mellitus: A meta-analysis. J Int Med Res. 2016; 44: 1156-73.

[11] Epel ES. Psychological and metabolic stress: a recipe for accelerated cellular aging? Hormones. 2009; 8(1); 7-22.

[12] Lipoeto NI, Agus Z, Oenzil F, Masrul M, Wattanapenpaiboon N. Contemporary minangkabau food culture in West Sumatra, Indonesia. Asia Pac J Clin Nutr. 2001; 10(1): 10-6.

[13] Hatma RD. Lipid Profiles Among Diverse Ethnic Groups in Indonesia. Acta Medica Indonesiana. 2011; 43(1): 4-11.

[14] Balasubramanyam M, Adaikalakoteswari A, Monickaraj SF, Mohan V. Telomere shortening \& metabolic/vascular diseases. Indian J Med Res. 2007; 125(3): 441-50.

[15] Khan S, Naidoo DP, Chuturgoon AA. Telomeres and atherosclerosis. Cardiovasc J Afr. 2012; 23(10): 563-571. 
[16] Murillo-Ortiz B, Albarran-Tamayo F, Arenas-Aranda D, Benitez-Bribiesca L, MalacaraHernandez JM, Martinez-Garza S, et al. Telomere length and type 2 diabetes in males, a premature aging syndrome. Aging Male. 2012; 15(1): 54-8.

[17] Lee SS, Bohrson C, Pike AM, Wheelan SJ, Greider CW. ATM kinase is required for telomere elongation in mouse and human cells. Cell Rep. 2015; 13(8): 1623-1632

[18] Simons MJP. Questioning causal involvement of telomeres in aging. Ageing Research Reviews. 2015; 24: 191-6.

[19] Needham BL, Adler N, Gregorich S, Rehkopf D, Lin J, Blackburn EH, Epel SS. Socioeconomic status, health behavior, and leukocyte telomere length in the National Health and Nutrition Examination Survey, 1999-2002. Soc Sci Med. 2013; 85:1-8.

[20] Carrero JJ, Stenvinkel P, Fellstrom B, Qureshi AR, Lamb K, Heimburger O, et al. Telomere attrition is associated with inflammation, low fetuin-A levels and high mortality in prevalent haemodialysis patients. Journal of Internal Medicine. 2007; 263: 302-12. 